ACADEMIA ROMÂNĂ
Revoum. Chim.,
Revue Roumaine de Chimie
http://web.icf.ro/rrch/

\title{
A NEW GREEN AND CATALYST FREE STRATEGY FOR SYNTHESIS OF CYANODIENONES USING TASK-SPECIFIC IONIC LIQUID
}

\author{
Fatemeh ABADAST ${ }^{\mathrm{a}}$, Arash MOURADZADEGUN ${ }^{\mathrm{a}, \mathrm{b} *}$ and Mohammad Reza GANJALI ${ }^{\mathrm{b}, \mathrm{c}}$ \\ ${ }^{a}$ Department of Chemistry, Faculty of Science, Shahid Chamran University of Ahvaz, Ahvaz, Iran \\ ${ }^{\mathrm{b}}$ Center of Excellence in Electrochemistry, University of Tehran, Tehran, Iran \\ ${ }^{\mathrm{c}}$ Biosensor Research Center, Endocrinology \& Metabolism Molecular-Cellular Sciences Institute, \\ Tehran University of Medical Sciences, Tehran, Iran
}

Task-specific ionic liquid, 1- $n$-butyl-3-methylimidazolium cyanide $([\mathrm{bmim}] \mathrm{CN})$, in the presence of [bmim] Br has been prepared and used for the first time as the medium as well as reagent for the synthesis of aromatic cyanodienones from the corresponding triarylpyrylium perchlorates by cyanide-halide exchange. The $[\mathrm{bmim}] \mathrm{CN}$ having a reactive anion, also could promote the desired reaction thereby reducing the reaction times and improving the yields substantially. The products could be easily isolated from the reaction mixture by simple extraction.

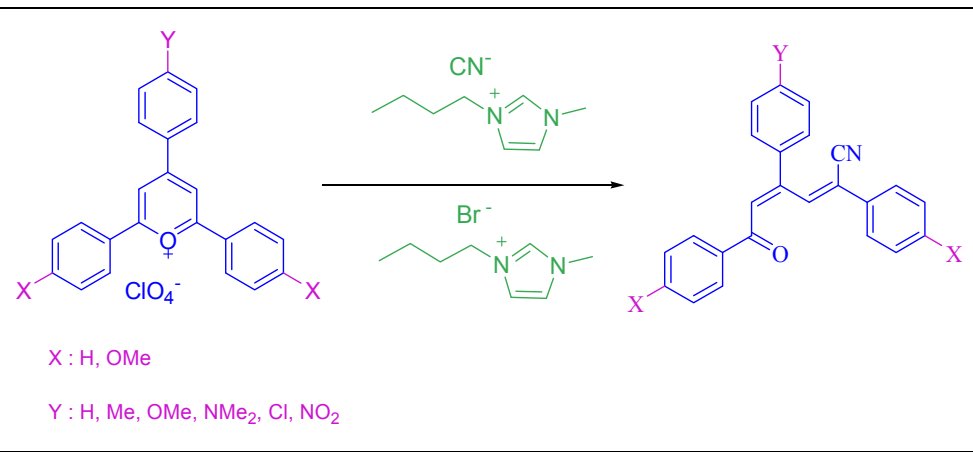

\section{INTRODUCTION}

Over the last decade, ionic liquids have attracted intensive interests due to their wide applications in synthesis, catalysis and chemical separations. ${ }^{1-5}$ Much of this interest has been focused on the development of ionic liquids as alternative green materials with applications including organic and inorganic synthesis, polymer synthesis, electrochemistry etc. ${ }^{6-8}$ The task-specific ionic liquids (TSILs) where a functional group is covalently tethered to the cation or anion (or both) of the ionic liquid, are the latest generation of ionic liquid. The incorporation of this functionality should imbue the ionic liquid with a capacity to behave not only as a reaction medium but also as a reagent or catalyst in some reactions or processes. ${ }^{9-10}$ TSILs also have the ability to dissolve a wide range of organic, inorganic and polymeric materials within their.

Aromatic cyanodienones are precursors for interesting heterocyclic compounds such as butenolides which have main roles in biological activities. ${ }^{11-19}$

The major drawbacks for the synthesis of these biologically important molecules starting from readily available triarylpyrylium perchlorates are much longer reaction times (e.g., $23 \mathrm{~h}$ for $1 \mathrm{G}$ ) and toxicity of cyanide anion leading to vomiting, convulsions, loss of consciousness and eventual death. ${ }^{20-22}$ Although our preceding efforts in the green synthesis of these compounds using cyanide impregnated on anion exchange $\operatorname{resin}^{23}$ and expeditious synthesis of these compounds using neutral alumina as a versatile heterogeneous catalyst, ${ }^{24}$ improved the reaction conditions, it is still a great challenge to construct these molecules

\footnotetext{
* Corresponding author: arash_m@scu.ac.ir; abadast_e@yahoo.com
} 
using a safe and simple method that can resolve the both drawbacks simultaneously.

Under this light and in continuation of ongoing work in our laboratory to develop selective, preparative and synthetically useful methodology for preparation, application and other transformation of pyrylium and thiopyrylium salts, ${ }^{25-28}$ we have accomplished, for the first time, the use of $[\mathrm{bmim}] \mathrm{CN} /[\mathrm{bmim}] \mathrm{Br}$ as a safe reagent and reaction medium for synthesis of aromatic cyanodienones.

\section{RESULTS AND DISCUSSION}

An improved procedure for the synthesis of various aromatic cyanodienones (2) from the reaction of triarylpyrylium perchlorates contain electron donor and withdrawing groups on para position of phenyl rings (1) with 1- $n$-butyl-3methylimidazolium cyanide as task-specific ionic liquid is described (Scheme 1).

Before introducing general protocol, preliminary tests were carried out to survey the requisite reaction conditions and establish the modifications required for this methodology.
Triphenylpyrylium perchlorate was chosen as the model compound to identify and optimize the reaction conditions.

Initially, the relative molar ratio nucleophile and substrate was optimized. In light of this affair, the reaction of model compound with varying amount of sodium cyanide in the presence of [bmim] Br as solvent were investigated. As it can be observed in Table 1, the target reaction is favored by increasing the nucleophile/substrate ratio as shown from the significant decrease in the reaction time. Bearing in mind that the reaction proceeds through an addition then ring opening mechanism, the increase in nucleophile concentration favors the first reaction step and, on the whole, the product formation. The decrease of the yield (76\%) by employing a ratio of 2.5 (entry 4) can probably be explained by generation of other products. So the best results were obtained when $2 \mathrm{mmol}$ of nucleophile and $1 \mathrm{mmol}$ of substrate were used (Table 1).

It is noteworthy that owing to the high toxicity of sodium cyanide, this method is not very environment-friendly.

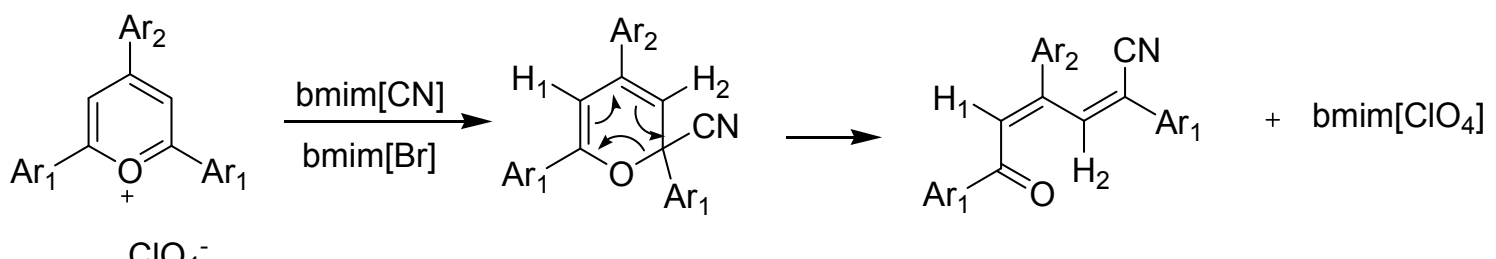

$$
\begin{aligned}
& \mathrm{Ar}_{1}: \mathrm{C}_{6} \mathrm{H}_{5}, \mathrm{C}_{6} \mathrm{H}_{4} p-\mathrm{OMe} \\
& \mathrm{Ar}_{2}: \mathrm{C}_{6} \mathrm{H}_{5}, \mathrm{C}_{6} \mathrm{H}_{4} p-\mathrm{Me}, \mathrm{C}_{6} \mathrm{H}_{4} p-\mathrm{OMe}, \mathrm{C}_{6} \mathrm{H}_{4} p-\mathrm{NMe}_{2}, \mathrm{C}_{6} \mathrm{H}_{4} p-\mathrm{Cl}, \mathrm{C}_{6} \mathrm{H}_{4} p-\mathrm{NO}_{2} \\
& \operatorname{bmim}[\mathrm{X}]: \underbrace{\mathrm{X}}_{\mathrm{X}^{-}} \mathrm{X}=\mathrm{CN}, \mathrm{Br}, \mathrm{ClO}_{4}
\end{aligned}
$$

Scheme 1 - Synthesis of aromatic cyanodienones (2) from the reaction of various triarylpyrylium perchlorates (1) with bmim[CN].

Table 1

Trend of the model reaction with different amount of $\mathrm{NaCN}$ in the presence of $[\mathrm{bmim}] \mathrm{Br}$ as solvent at $80{ }^{\circ} \mathrm{C}$

\begin{tabular}{cccc}
\hline Entry & {$[\mathbf{N u}] /[\mathbf{S u b}]$} & Time (h) & Yield of (2) (\%) \\
\hline 1 & 1 & 6 & 87 \\
2 & 1.5 & 4 & 87 \\
3 & 2 & 3 & 87 \\
4 & 2.5 & 1 & 76 \\
\hline
\end{tabular}


Table 2

Reaction of the model compound $\mathbf{1 A}$ with two different types of reagents

\begin{tabular}{cccc}
\hline Entry & Solvent & Nucleophilic source & Time \\
\hline 1 & {$[\mathrm{bmim}] \mathrm{Br}$} & $\mathrm{NaCN}$ & $3 \mathrm{~h}$ \\
2 & {$[\mathrm{bmim}] \mathrm{Br}$} & {$[\mathrm{bmim}] \mathrm{CN}$} & $30 \mathrm{~min}$ \\
\hline
\end{tabular}

Table 3

The conversion of various triarylpyrylium salts into corresponding cyanodienones at $80^{\circ} \mathrm{C}$

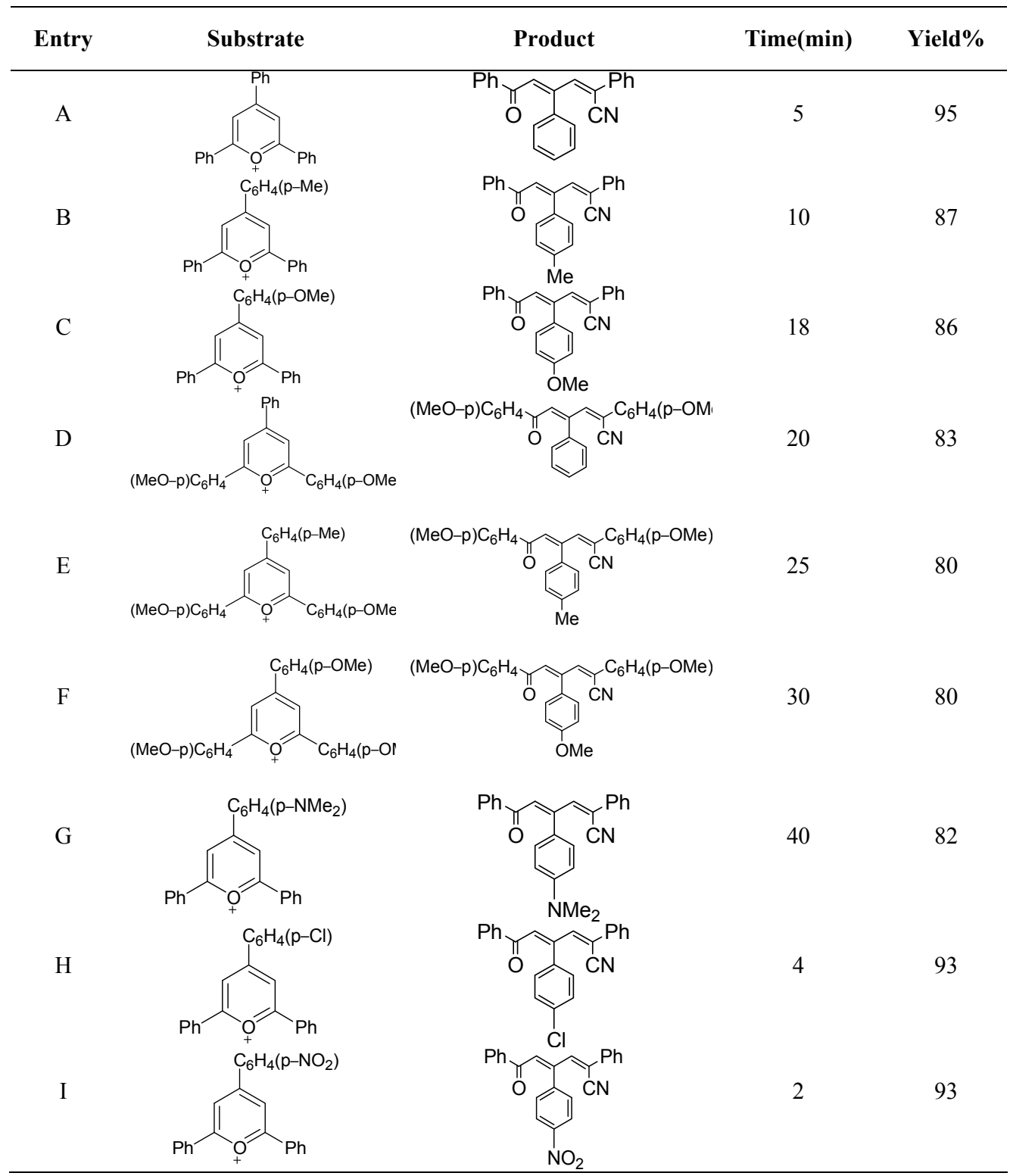

To circumvent this dilemma and reduce the toxicity of cyanide ion, the attention was shifted to the design, synthesis and use of new cyanide source that not only possesses high activity and selectivity, but is also simultaneously benign to the environment. Accordingly, a new synthetic strategy commenced with the synthesis of new task-specific ionic liquid was carried out.
Task-specific ionic liquid [bmim] CN was prepared according to a modified literature procedure. ${ }^{32}$

The use of this task-specific ionic liquid as reagent decreases the reaction time (Table 2).

This indicated that the nucleophilicity of the cyanide ion is much higher in $[\mathrm{bmim}] \mathrm{CN}$ compared to $\mathrm{NaCN}$. This has been attributed to the fact that reactivity of the cyanide ion mainly 
depends on counterion. Probably, Coulomb interactions, which are maximized in solvent media, lower the reactivity of the nucleophile when the counterion is the smaller $\mathrm{Na}^{+}$cation, while the bigger 1- $n$-butyl-3-methylimidazolium cation has less interaction with cyanide ion.

On the other hand, driving force of target reaction could be explained by the concept of hard and soft acids and bases (HSAB). Hence, due to the overall hard nature the bmim cation, ion paring is preferred with a hard anion, such as perchlorate.

In the presence of $[\mathrm{bmim}] \mathrm{CN}$ alone, a small amount of starting material remained intact. So, in Additional tests, reaction of model substrate with $[\mathrm{bmim}] \mathrm{CN}$ in the presence of $[\mathrm{bmim}] \mathrm{Br}$ were carried out. In $[\mathrm{bmim}] \mathrm{CN} /[\mathrm{bmim}] \mathrm{Br}$ mixture the reaction was very fast and gave corresponding cyanodienone in $95 \%$ yield within 5 minutes. Thus $[\mathrm{bmim}] \mathrm{CN} /[\mathrm{bmim}] \mathrm{Br}$ appears as the best reagent giving the best results.

These extraordinary results promoted us to demonstrate the efficiency and the applicability of the present method. Therefore, the reaction was performed for a variety of triarylpyrylium perchlorates with $[\mathrm{bmim}] \mathrm{CN} /[\mathrm{bmim}] \mathrm{Br}$ mixture in which corresponding aromatic cyanodienones with excellent yields were obtained (Table 3). The structure of all products were settled from their physical and spectroscopic (IR, ${ }^{1} \mathrm{HNMR},{ }^{13} \mathrm{CNMR}$ ) data (see ESI).

As shown in table 3, electron donor groups cause the reactions to become slow (e.g., entry A until G). This may be described by considering the fact that these groups decrease positive charge on $\alpha$-position of heterocyclic ring. The more electron donor groups, exhibit the greater reaction time. In contrast electron withdrawing groups (e.g., entry $\mathrm{H}$ and I) accelerate the reactions.

Since the products were fairly soluble in the ionic liquid, they could be easily separated by simple extraction with ether. More importantly, there is no formation of any side-products in this process and there is no need for column chromatography for the purification of the products.

\section{EXPERIMENTAL}

\section{General}

Chemicals were purchased from Fluka, Merck, and Aldrich chemical companies. Monitoring of the reactions was accomplished by thin-layer chromatography (TLC). Infrared (IR) spectra were obtained on a Bomen MB:102 FT-IR spectrophotometer. ${ }^{1} \mathrm{H}$ NMR and ${ }^{13} \mathrm{C}$ NMR spectra were recorded on a Brucker spectrometer at 400 and $100 \mathrm{MHz}$, respectively, in $\mathrm{CDCl}_{3}$ with tetramethylsilane as an internal standard. Mass spectra (MS) were measured on Anagilent 5975 mass spectrophotometer.

\section{Synthesis of triarylpyrylium perchlorates}

All triarylpyrylium perchlorates were synthesized from the corresponding aldehydes and ketones by the method previously described. ${ }^{29-30}$ Briefly, corresponding benzaldehyde $(0.1 \mathrm{~mol})$ and acetophenone $(0.2 \mathrm{~mol})$ were stirred at room temperature, and sulfuric acid $(6 \mathrm{~mL})$ was added dropwise during $30 \mathrm{~min}$. The mixture was stirred at $100{ }^{\circ} \mathrm{C}$ for $60 \mathrm{~min}$. Then, ethanol $(200 \mathrm{~mL})$ and perchloric acid $70 \%(10 \mathrm{~mL})$ were added. The mixture was excluded to form a precipitate for $24 \mathrm{~h}$. The precipitates recrystallized from acetic acid.

\section{Synthesis of [bmim]Br}

A mixture of 1-methylimidazole $(4.1 \mathrm{~g}, 0.05 \mathrm{~mol})$ and 1-bromobutane $(6.85 \mathrm{~g}, 0.05 \mathrm{~mol})$ in absence of solvent was heated with stirring at $80^{\circ} \mathrm{C}$ for $3 \mathrm{~h}$. Then, the product was washed with dimethyl ether and dried in vacuum to afford [bmim]Br. ${ }^{31}$

\section{Synthesis of [bmim] CN}

[bmim] $\mathrm{CN}$ was prepared according to a modified literature procedure. $^{32}$ [bmim]BF $4(500 \mathrm{mg}, 2.21 \mathrm{mmol})$ was added at ambient temperature to $\mathrm{KCN}(144 \mathrm{mg}, 2.21 \mathrm{mmol})$ in ethanol/water (1:1). The mixture was stirred for $2 \mathrm{~h}$ and then filtered. The filtrate was dried in vacuo at $40{ }^{\circ} \mathrm{C}$ for $30 \mathrm{~min}$, yielding $300 \mathrm{mg}$ [bmim]CN (1.81 mmol, 82\%) as pale yellowish liquid.

\section{General procedure for the synthesis of aromatic cyanodienones}

Reactions were typically carried out by addition of $1 \mathrm{mmol}$ triarylpyrylium perchlorates to $2 \mathrm{mmol}$ ionic liquid [bmim] CN in $10 \mathrm{ml}[\mathrm{bmim}] \mathrm{Br}$ and heated to $80^{\circ} \mathrm{C}$. After completion of reaction, as indicated by TLC, products was extracted from the reaction mixture using diethyl ether. Then, diethyl ether was evaporated under vacuum and residual recrystalized in $\mathrm{EtOH}$.

\section{CONCLUSIONS}

A novel $[\mathrm{bmim}] \mathrm{CN} /[\mathrm{bmim}] \mathrm{Br}$ system was proved to be an effective reagent for the synthesis of various aromatic cyanodienones starting from corresponding triarylpyrylium perchlorates by playing the triple role of nucleophile, solvent and promoter. This environmentally friendly methodology offers marked improvements with regard to operational simplicity, short reaction times, easy workup, high isolated yields of products, greenness of the procedure also avoiding hazardous organic solvent and toxic catalyst.

Acknowledgments. This work was supported by the Research Council at the University of Shahid Chamran. 


\section{REFERENCES}

1. T. Welton, Chem. Rev., 1999, 99, 2071-2084.

2. P. Wassercheid and W. Keim, Angew. Chem., Int. Ed, 2000, 39, 3772-3789.

3. J. H. Davis and P. Fox, Chem. Commun., 2003, 1209-1212.

4. F. van Rantwijk and R. A. Sheldon, Chem. Rev., 2007, 107, 2757-2785.

5. Y. Gua and G. Li, Adv. Synth. Catal., 2009, 351, 817-847.

6. R. C. Buijsman, E. V. Vuuren and J. G. Serrenburg, Org. Lett., 2001, 3, 3785-3787.

7. P. Kubisa, Prog. Polym. Sci., 2004, 29, 3-15.

8. L. A. Blanchard, D. Hancu, E. J. Beckman and J. F. Brennecke, Nature, 1999, 399, 28-29.

9. T. V. Hoogerstraete, B. Onghena and K. Binnemans, J. Phys. Chem. Lett., 2013, 4, 1659-1663.

10. J. H. Davis, Chem. Lett., 2004, 33, 1072-1077.

11. A. T. Balaban, A. Tudose and M. T. Caproiu, Tetrahedron, 2003, 59, 3291-3295.

12. L. J. Harris, N. J. Alexander, A. Saparno, B. Blackwell, S. P. McCormick, A. E. Desjardins, L. S. Robert, N. Tinker, J. Hattori, C. Piche, J. P. Schernthaner, R. Watson and T. Ouellet, Fungal Genet. Biol., 2007, 44, 293-306.

13. X. Zhang, J. Guo and S. Hu, Synth. Commun., 2012, 42, $1551-1558$.

14. N. N. Karade, S. V. Gampawar, J. M. Kondre and S. V. Shinde, Tetrahedron Lett., 2008, 49, 4402-4404.

15. G. Sabitha, M. N. Prasad, M. Ramesh and J. S. Yadav, Monatsh. Chem., 2010, 141, 1245-1250.

16. W. Y. Fan, Z. L. Wang, Z. G. Zhang, H. C. Li and W. P. Deng, Tetrahedron, 2011, 67, 5596-5603.

17. B. Clark, R. J. Capon, E. Lacey, S. Tennant, J. H. Gill, B. Bulheller and G. Bringmann, J. Nat. Prod., 2005, 68, 1226-1230.
18. J. Wu, Q. Zhu, L. Wang, R. Fathi and Z. Yang, J. Org. Chem., 2003, 68, 670-673.

19. G.-F. Du, L. He, C.-Z. Gu and B. Dai, Synth. Commun., 2012, 42, 1226-1233.

20. Y. H. Kim and J. I. Hong, Chem. Commun., 2002, 512-513.

21. M. Tomasulo, S. Sortino, A. J. P. White and F. M. Raymo, J. Org. Chem., 2006, 71, 744-753.

22. K. S. Lee, H. J. Kim, G. H. Kim, I. Shin and J. I. Hong, Org. Lett., 2008, 10, 49-51.

23. A. Mouradzadegun and F. Abadast, Monatsh. Chem., 2013, 144, 375-379.

24. A. Mouradzadegun and F. Abadast, Synth. Commun., 2014, 44, 640-647.

25. A. Mouradzadegun and S. Dianat, J. Heterocycl. Chem., 2009, 46, 778-781.

26. A. Mouradzadegun and F. Abadast, Tetrahedron Lett., 2013, 54, 2641-2644.

27. A. Mouradzadegun and F. Abadast, Synlett, 2014, 25, 448-452.

28. A. Mouradzadegun and F. Abadast, Chem. Commun., 2014, 50, 15983-15986.

29. A. T. Balaban, A. Dinculescu, G. N. Dorofeenko, G. W. Fischer, A. V. Koblik, V. V. Mezheritskii and W. Schroth, "Advances in Heterocyclic Chemistry", A. R. Katritzky (Ed.), Academic: New York, 1982, vol. 2, suppl 1.

30. A. T. Balaban, W. Schroth and G. W. Fischer, "Pyrylium salts", in "Advances in Heterocyclic Chemistry", A.R. Katritzky (Ed.), Academic: New York, 1969, vol. 10, p. 241, and references therein.

31. D. Goswami, A. Chattopadhyay, A. Sharma and S. Chattopadhyay, J. Org. Chem., 2012, 77, 11064-11070.

32. A. Hinz and M. Köckerling, Z. Anorg. Allg. Chem., 2015, $641,1347-1351$. 
